\title{
Representation of Users and Uses of English in Beginning Japanese EFL Textbooks
}

\author{
Aya Matsuda \\ University of New Hampshire
}

This study explores the representation of English users and uses in Japanese EFL textbooks for seventh graders that have been approved by the Ministry of Education. Analysis of the nationality of the main characters and the contexts and types of English use featured in the chapters suggests that the textbooks tend to emphasize the inner circle (Kachru, 1985) both in intranational and international use. The representation of users and uses in other contexts, particularly of those in the outer circle, is much more limited despite the growing recognition of the spread of English and the increased use of English outside of the inner circle (Crystal, 1997; Graddol, 1997). Based on the findings, I discuss the extent to which these textbooks represent the current global uses and users of English, consider the appropriateness of the representation, and suggest ways to help English learners become more aware of the sociolinguistic complexity of the English language.

本研究では、中学一年生対象の検定教科書 7 冊において、英語使用者および 用途がどのように表現されているかを調査した。登場人物の国籍と各課に含ま れる英語使用の状況と種類を分析したところ、国内言語・国際言語両方の使用 において Inner Circle (Kachru, 1985) の英語話者と彼らの英語使用に重点をおく傾 向があることがわかった。同時に、それ以外の状況、特に Outer Circle での英語 使用と英語話者は、教科書内での表現はあまりみられなかった。本論文では、 この結果をふまえ、教科書が現在世界における英語が果たしている役割をいか に正確に表しているかを議論し、その適切さを考察するとともに、英語の複雑 な社会言語学的背景の理解を促す方法を提示した。

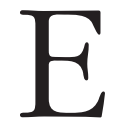

nglish performs a wide variety of functions in different parts of the world. In the inner circle (i.e., Australia, Canada, New Zealand, the United Kingdom, and the United States) (Kachru, 1985),

JALT Journal, Vol. 24, No. 2, November, 2002 
the majority of people learn English as their first language. Even when they speak another language at home, English is likely to become their dominant language because of the extended exposure to the language outside the home and the numerous functions the language performs in society. In outer circle countries and regions such as India, Singapore, and Nigeria, which are former colonies of inner circle countries, English is institutionalized. That is, English has acquired an extended range of uses in intranational communication (e.g., language of law, medium of education), linguistic nativization has taken place, and literary works are created in that variety of English, although other languages (usually indigenous languages) still maintain important functions (Kachru, 1992). In the expanding circle, people learn English as a foreign language and use it predominantly for international, rather than intranational, communication. Furthermore, English does not have the extended functions it has in the inner or outer circle.

In addition to the increase in its functions, the worldwide spread of English has changed the demographics of the population of English users. English is not used exclusively among native English speakers or between native and nonnative English speakers anymore, but also often for communication among so-called nonnative speakers of English (Graddol, 1997; Smith, 1983; Widdowson, 1994). ${ }^{1}$ Because it is increasingly used among people who were traditionally regarded as nonnative speakers, i.e., speakers from the outer and expanding circles, the assumption that nonnative English speakers learn English in order to communicate with native English speakers and learn about their culture does not always hold true anymore. In fact, the role of nonnative speakers in shaping the form and functions of the English language has increased. As Graddol (1997) states, "native speakers may feel the language 'belongs' to them, but it will be those who speak English as a second or foreign language who will determine its world future" (p. 5).

This worldwide spread and the consequent changes, such as the expansion and complications in the variety of uses and the increasing uses among nonnative speakers, are important characteristics of the English language. Consequently, acknowledging all of these functions of the language is essential for understanding the sociolinguistic complexity of the English language.

However, in Japan and perhaps also in other countries in the expanding circle, many English learners and even some teachers still perceive English exclusively as the language of the inner circle and the purpose of learning English to be merely to access the inner circle culture. For 
instance, a qualitative case study of Japanese secondary school students (Matsuda, forthcoming) suggested that, although they perceived English to be an international language in the sense that it is being used internationally, they did not believe it belonged to the world at large. Rather, the students perceived the language as the property of native English speakers (Americans and British, more specifically) and believed that the closer they followed native speakers' usage, the better. Their awareness of outer circle countries, including the forms and functions of English used in them, was extremely limited (see Friedrich, 2000, for a similar example from Brazil).

The picture of English uses and users that these Japanese students had is incomplete in the sense that it does not acknowledge the increase in the use of English among so-called nonnative speakers of English, and thus is problematic for several reasons. First, if students do not understand the significance of the uses of English among nonnative speakers, they cannot fully take advantage of the opportunities that accompany the use of English as an international language. Instead, students may assume that English belongs to the inner circle and that others, who are expected to conform to inner circle norms, should remain in an oppressed, peripheral position in international communication in English.

Secondly, such a limited perception of the English language may lead to confusion or resistance when students are confronted with different types of English users or uses (e.g., users from the outer circle). Students may be shocked by varieties and uses of English that deviate from the inner circle English, view them as deficient rather than different, or be disrespectful of such varieties and uses. Lastly, a limited understanding of the users and uses of the language may have a negative effect on language acquisition. A language is not merely a combination of discrete linguistic and metalinguistic knowledge, but rather, it is a dynamic system embedded in a social context (Halliday, 1978; Berns, 1990). Therefore the awareness of the context of English, including its worldwide spread, the consequent diversity in its forms and functions, and its increased use among so-called nonnative speakers, can be considered crucial for understanding and acquiring the language.

One of the possible sources of influence on students' perception of English is their English class, where students are intensively exposed to the target language. Textbooks, in particular, can be a significant source of exposure to various users and uses of English and may play a vital role in the construction of students' perceptions of the English language because they play an important role in EFL classrooms. Hino (1988), in 
his study of the representation of nationalism in Japanese EFL textbooks from different historical periods, argued that textbooks not only disseminate knowledge but also express, reinforce, and construct a certain view of the world. Such influence may be especially strong in Japan, where textbooks, which are approved by the national government and selected by the local school district, have institutional authority and where classroom lessons tend to be constructed closely around the textbooks. In addition, EFL students tend to perceive their textbooks as high prestige sources of input because they do not receive much input outside the classroom (Bardovi-Harlig, 1996). All these factors make textbooks an influential source of input for students and a logical place to begin an inquiry about the presentation of English in Japanese EFL classrooms and the construction of students' beliefs and perceptions of the English language.

The current study explores the representation of English users and uses in beginning EFL textbooks used in the first year of junior high school (7th grade) in Japan. Specifically, the following research questions were investigated:

1. What kinds of people are represented as English users in 7th-grade Japanese EFL textbooks?

2. What kinds of English uses are represented in these textbooks?

Based on the findings, I will discuss how thoroughly these textbooks represent the current global uses and users of English, consider the appropriateness of the representation, and suggest ways to help English learners raise their awareness of the sociolinguistic complexity of the English language.

\section{Methodology \\ Textbook Selection}

The current study analyzed all seven 7th-grade textbooks that were approved by Monbusho² (the Ministry of Education) in 1996 and were in use from April 1997 to March 2002. 
Table 1: List of Textbooks

\begin{tabular}{ll}
\hline Title & Publisher \\
\hline Columbus English Course 1 (CO) & Mitsumura Tosho \\
Everyday English 1 (EE) & Chukyo Shuppan \\
New Crown English Series New Edition 1 (NC) & Sanseido \\
New Horizon 1 (NH) & Tokyo Shoseki \\
One World 1 (OW) & Kyoiku Shuppan \\
Sunshine 1 (SS) & Kairyudo \\
Total English 1 (TE) & Shubun Shuppan \\
\hline
\end{tabular}

I chose to analyze Monbusho-approved textbooks because of the significant role they play in English classrooms across the country. All public elementary and secondary schools in Japan are required to follow the national curriculum and use textbooks that are approved by the Ministry of Education. Even private schools, which are not required to follow the national curriculum, often adopt a Monbusho-approved textbook as one of their primary textbooks. Therefore, virtually all secondary school students, including the participants of the aforementioned study on the perception of the ownership of English (Matsuda, forthcoming), come in contact with Monbusho-approved textbooks in their English classes.

In addition, because the Monbusho only approves textbooks that closely follow the national curriculum, the approved textbooks often become the curriculum itself. Even at private schools, where more flexibility is allowed in the selection of teaching materials than in public schools, some lessons follow the structure of Monbusho-approved textbooks closely and do not involve any outside materials (see Matsuda, 2000a). While I would not claim that this is the case for all English curricula in Japan, it can be said that Monbusho-approved textbooks play a large role in the EFL curriculum at Japanese secondary schools, and that is the primary reason for selecting Monbusho-approved textbooks for the current study.

Among all Monbusho-approved English textbooks, seventh-grade textbooks were selected because they provide the first formal encounter that most students have with English, and thus the explicit and implicit messages they send about the users and uses of English potentially have a strong influence on students' perceptions of English.

The contents of all seven textbooks that were reviewed are organized 
in a similar manner. Each has 11 to 15 chapters consisting of the main text (usually a dialogue that introduces new vocabulary and sentence structures) and tasks related to the new function or sentence structures introduced in the main text. Summaries of grammar points and informational notes about English speaking cultures are presented at the end of each chapter, after every few chapters, or at the end of the textbook. Additional readings, poems, songs, word lists, alphabet tables, and pronunciation guides are found between chapters or at the end of the textbook.

\section{Analysis}

In order to understand the representation of users and uses of English in Japanese EFL textbooks, the main characters in the textbooks and the contexts and types of English uses presented in the chapters were investigated.

The first research question of the study was "What kinds of people are represented as English users in seventh-grade Japanese EFL textbooks?" In order to answer this question, I identified the nationality of the main characters, who were introduced in the early sections of each textbook before the regular chapters began. I also counted the number of words uttered by each character.

The second research question was "What kinds of English uses are represented in seventh-grade Japanese EFL textbooks?" To address this question, the contexts and types of English uses represented in the main texts of the chapters were identified and analyzed. The analysis of the contexts involved the identification of countries in which characters used English. The contexts represented in the textbooks included (1) Japan, (2) inner circle countries, (3) outer circle countries, (4) expanding circle countries other than Japan, (5) multiple contexts (e.g., international phone calls and letters that involved more than one of the above four contexts), (6) fictional contexts (e.g., in a time machine), and (7) unknown/no context (e.g., introduction of numbers). For each context type, I counted the number of chapters that included English uses taking place in that context. Dialogues on an international flight were categorized by the country of destination.

Types of English use can be defined and classified in various ways, but in this study, I decided to focus on whether the use is intranational or international. Intranational use in this study is defined as the use of English between people from the same country, while international use refers to use between people from different countries. Intranational use 
is further divided into three types: between people from the same inner circle country, between people from the same outer circle country, and between people from the same expanding circle country. International use is also further divided into three types: between people from different inner circle countries (i.e., native speakers from different countries), between native speakers and nonnative speakers (i.e., people from the outer or expanding circle) of English, and exclusively among nonnative speakers of English ${ }^{3}$. Figure 1 illustrates the six types of English uses whose representation was investigated in this study.

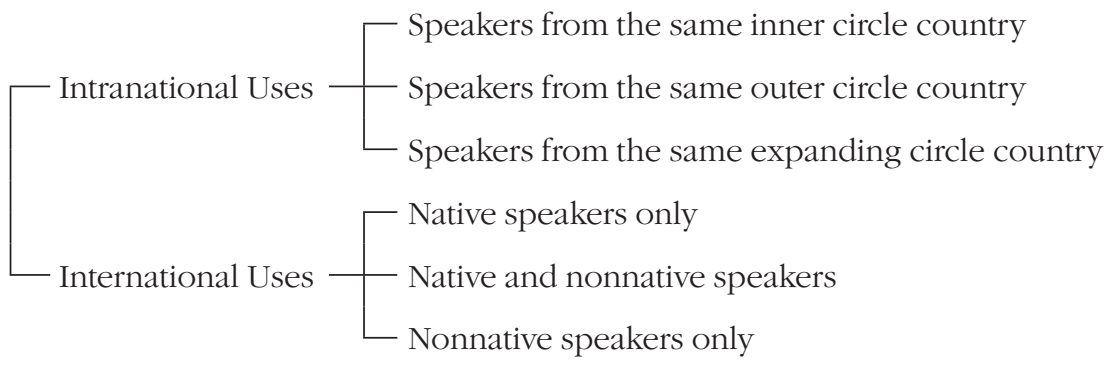

Figure 1: Types of English Uses

To test the reliability of the coding scheme for the analysis of contexts and types of uses, I trained an outside coder and asked him to analyze one textbook with 13 chapters (14.6\% of all chapters analyzed). Interrater agreement figures of 0.94 and 0.93 were achieved for the analysis of contexts and the analysis of types of uses, respectively.

Furthermore, the additional reading passages, poems, songs, word lists, cultural notes, and pictorial images were also studied in order to supplement the analysis.

\section{Results and Discussion Nationality of the Main Characters}

Table 2 shows where the main characters in each textbook came from and the number of words uttered by those characters in the main text. 
Table 2: Nationality of the Main Characters and the Number of Words Uttered by those Characters

\begin{tabular}{lcclcc}
\hline Textbook & Japan & IC & OC & EC Other than Japan & Unknown \\
\hline CO & $9(456)$ & $4(586)$ & 0 & 0 & 0 \\
EE & $3(463)$ & $4(341)$ & 0 & $1(120)$ & $2(88)$ \\
NC & $10(582)$ & $1(212)$ & $1(70)$ & $3(81)$ & 0 \\
NH & $3(258)$ & $3(258)$ & 0 & $1(218)$ & 0 \\
OW & $2(348)$ & $5(396)$ & $1(143)$ & 0 & $1(17)$ \\
SS & $4(257)$ & $9(523)$ & 0 & 0 & 0 \\
TE & $3(480)$ & $4(758)$ & 0 & 0 & $3(105)$ \\
Total & $34(2844)$ & $30(3074)$ & $2(213)$ & $5(419)$ & 0 \\
\hline
\end{tabular}

Note: Number of words uttered is in parentheses

The majority of the 74 main characters are from Japan (34) or inner circle countries including the U.S., Canada, Australia, and Scotland (30). The number of characters from the outer circle (one each from Hong Kong ${ }^{4}$ and Kenya) and the expanding circle other than Japan (a total of five, with one from Indonesia, three from China, and one from Brazil) are relatively few. The comparison of the number of words uttered shows a similar pattern, with slightly greater emphasis on the inner circle characters. Japanese characters outnumber inner circle characters by four but they produce fewer words (2,844 words) than those from the inner circle (3,074 words). Characters from the outer circle and expanding circle countries other than Japan produce only 213 words and 419 words, respectively.

This dominant representation of speakers from Japan and the inner circle is found in individual textbooks as well. The only exception is New Crown (Morizumi, 1997), which has more speakers from the expanding circle (ten Japanese and three others) than the inner circle (one person) or the outer circle (one person). However, it should be noted that even in this textbook, the number of words uttered by the only inner circle speaker (212 words) is still much larger than that of the only outer circle speaker (70 words) or that of the three speakers from expanding circle countries other than Japan (81 words).

The large number of inner circle characters in all the textbooks reviewed, except for the one just mentioned above, gives the impression that they are the dominant users of English. Japanese main characters are also numerous, but due to the limited number of examples of intra- 
national use included in the texts, they do not come across as regular and extensive users of English but rather as prototypical examples of EFL learners, similar to the textbooks' audience. In contrast, representation of users from the outer circle and expanding countries other than Japan is limited in terms of both the number of characters and their roles in dialogues. This does not seem to reflect growing recognition of the spread of English (Crystal, 1997; Graddol, 1997) and sends the message that English users from the outer and expanding circles hold only peripheral roles in the use of English worldwide.

\section{Contexts of English Use}

Table 3 illustrates the number of chapters in the reviewed textbooks that include examples of English use in each context. Use in Japan and the inner circle is represented more often than use in the outer circle or expanding circle countries other than Japan.

Table 3: Contexts of English Uses

\begin{tabular}{lccccccc}
\hline Textbook & Japan & IC & OC & $\begin{array}{c}\text { EC Other } \\
\text { than Japan }\end{array}$ & Multi-Context & Fictional & $\begin{array}{c}\text { Unknown/ } \\
\text { No Context }\end{array}$ \\
\hline CO & 13 & 0 & 0 & 0 & 0 & 0 & 0 \\
EE & 10 & 0 & 0 & 0 & 2 (J-IC) & 4 & 1 \\
NC & 10 & 0 & 0 & 0 & 0 & 1 & 0 \\
NH & 7 & 0 & 0 & 0 & 0 & 5 & 0 \\
OW & 1 & 9 & 1 & 0 & $2(\mathrm{~J}-\mathrm{IC} ; \mathrm{J}-\mathrm{OC})$ & 0 & 2 \\
SS & 5 & 7 & 0 & 0 & 1 (J-IC) & 0 & 1 \\
TE & 11 & 1 & 0 & 0 & 0 & 0 & 0 \\
Total & 57 & 17 & 1 & 0 & 5 & 10 & 4 \\
\hline
\end{tabular}

Japan is the most common context for English use in five of the seven individual textbooks as well as in the overall distribution in all the textbooks combined. For instance, all dialogues in Columbus (Togo \& Matsuno, 1997) and most dialogues in Total (Horiguchi, Goris, \& Yada, 1997) are between Japanese students and their American friends or teachers living in Japan. Use in the inner circle is represented in more than half of the chapters in Sunshine (Shimaoka, Aoki, Matsuhata, \& Wada, 1997) and One World (Sasaki, 1997), in which the main characters visit the U.S. and Australia, inner circle countries, and use English to communi- 
cate with people there. Four out of five "multi-context" examples also involved Japan and an inner circle country. In contrast, use in the outer circle and expanding circle countries other than Japan is represented much less frequently than use in Japan and the inner circle. Of all the textbooks, only One World (Sasaki, 1997) includes a chapter that features the use of English in an outer circle country, Hong Kong. English use in expanding circle countries other than Japan is not represented in any of the textbooks.

Thus, representation of the contexts of English use emphasizes the use of English in the inner circle and Japan rather than the use of English in the outer circle and other expanding circle countries.

\section{Types of Uses I: Intranational vs. International Use}

Table 4 compares the number of chapters in each textbook that include intranational use among speakers from the same countries and ones that include international use between English users from different countries.

Table 4: Intranational vs. International Uses

\begin{tabular}{ccc}
\hline Textbook & Intranational Uses & International Uses \\
\hline CO & 1 & 11 \\
EE & 3 & 10 \\
NC & 0 & 10 \\
NH & 0 & 11 \\
OW & 2 & 10 \\
SS & 2 & 10 \\
TE & 3 & 11 \\
Total & 11 & 73 \\
\hline
\end{tabular}

International use is represented more commonly than intranational use. The majority of chapters, amounting to at least ten chapters in each textbook and 73 of 89 chapters overall, include some representation of international use of English. Intranational use, on the other hand, is represented in only 11 chapters overall and not found at all in New Crown (Morizumi, 1997) or New Horizon (Asano, Makino, \& Shimomura, 1997). References to the international status of English in sections of the 
textbook other than the chapter dialogues are also found. For example, a note in the appendix of Sunshine (Shimaoka et al., 1997) states that "English can be considered an international language because it is used in various parts of the world" (p. 102), and a cultural note in One World (Sasaki, 1997) encourages students to "broaden [their] 'world' through learning English, which is one of the common languages of the world" (p. 95). ${ }^{5}$ The prominence of the presentation of the international use of English in these textbooks seems to emphasize the language's role as an international language. This representation makes sense considering that these textbooks are used in Japan, where English is not used for daily intranational communication, but mainly for international communication (Yano, 1992). ${ }^{6}$

\section{Types of Uses II: Intranational Use}

Table 5 compares the number of chapters representing each of the three types of intranational use: use among people from the same inner circle country, use among people from the same outer circle country, and use among the speakers from the same expanding circle country.

Table 5: Three Types of Intranational Uses

\begin{tabular}{llll}
\hline Textbook & IC & OC & EC \\
\hline CO & 1 & 0 & 0 \\
EE & 1 & 0 & 2 \\
NC & 0 & 0 & 0 \\
NH & 0 & 0 & 0 \\
OW & 2 & 0 & 0 \\
SS & 2 & 0 & 0 \\
TE & 3 & 0 & 0 \\
Total & 9 & 0 & 2 \\
\hline
\end{tabular}

The majority of intranational use takes place among inner circle English users. Nine out of ten chapters that present some kind of intranational use include the use of English between the inner circle English speakers. For example, Columbus (Togo \& Matsuno, 1997) depicts an American boy and his parents speaking English at the breakfast table, 
and in Sunshine (Shimaoka et al., 1997), Emily calls her family in New York and talks to them in English. In addition, some textbooks include pictures and texts that refer to the customs and cultures of inner circle countries and their people. New Crown (Morizumi, 1997), New Horizon (Asano et al., 1997), and Columbus (Togo \& Matsuno, 1997) have pictures of American school life, and a chapter on numbers from One World (Sasaki, 1997) lists emergency telephone numbers from four inner circle countries only: the U.S., U.K., Australia, and New Zealand.

References to intranational use involving speakers from the other two circles are also present in the textbooks, especially in sections other than the regular chapters. For example, five of seven textbooks have preliminary pages that introduce "Classroom English," and four of them include exchanges between Japanese students and a Japanese teacher of English, representing intranational use between speakers from the expanding circle. Also, some comments and maps refer to the use of English in the outer circle: a list of countries and languages spoken in each country mentioned in the textbook in New Crown (Morizumi, 1997) shows English as one of the languages spoken in the outer circle countries included, and a map in Total (Horiguchi et al., 1997) uses different colors to indicate the countries where English is the dominant language (the inner circle) and those where English is a lingua franca (the outer circle). While these lists and maps do not elaborate on the use of English in those countries, they at least acknowledge the use of English in the outer circle.

However, in the main texts, the representation of intranational use among people from the outer and expanding circle is limited. Only two chapters include the representation of intranational use between people from Japan, an expanding circle country, specifically dialogues between a Japanese main character and her mother. Intranational use in the outer circle is not represented at all in any of the chapter dialogues.

The extensive presentation of the use of English among people from the inner circle, combined with pictures and texts that refer to the inner circle cultures, sends a message that English is most closely associated with the inner circle. The role of English as an intranational language for those from the inner circle may also be implied when English is presented as one of many languages in the world. For example, a section in Columbus (Togo \& Matsuno, 1997) that features photos from Mali, Russia, Spain, Mexico, Kuwait, Brazil, and the U.S. with their dominant languages printed as the caption may suggest to students that one function of English is intranational use in the U.S. 
On the other hand, in Japan, English is not used regularly or extensively in daily communication. Thus, the presentation of English use among Japanese characters in textbooks may represent the limited but increasing use of English as a medium of English instruction (e.g., classroom English) and encourage students to use and practice English outside the classroom (e.g., to write poems or to keep diaries).

In sum, the analysis of intranational uses demonstrates that the representation of the use of English between inner circle users is much more common than other types, especially the use of English among speakers from the outer circle.

\section{Types of Uses III: International Use}

Table 6 shows the number of chapters that include presentation of the three types of international use: exclusively among native English speakers, between native and nonnative speakers of English, and exclusively among nonnative English speakers.

Table 6: Three Types of International Uses

\begin{tabular}{lccc}
\hline Textbook & NS Only & Both NS and NNS & NNS Only \\
\hline CO & 0 & 11 & 0 \\
EE & 0 & 8 & 2 \\
NC & 0 & 7 & 3 \\
NH & 0 & 11 & 1 \\
OW & 0 & 9 & 1 \\
SS & 0 & 9 & 2 \\
TE & 0 & 11 & 0 \\
Total & 0 & 66 & 9 \\
\hline
\end{tabular}

The overwhelming majority of the chapters present international use between one or more native speakers and one or more nonnative speakers of English. Such use was represented in all of the textbooks reviewed. Dialogues between Japanese students and their American teacher or friends, for example, are the only type of international use in Total (Horiguchi et al., 1997) and Columbus (Togo \& Matsuno, 1997). In Sunshine (Shimaoka et al., 1997) and One World (Sasaki, 1997), the main characters use English extensively to talk to native speakers when they 
visit the U.S. and Australia, inner circle countries.

Five of seven textbooks also present some English use exclusively among nonnative speakers, including a dialogue between a Kenyan student and Japanese students in New Crown (Morizumi, 1997), dialogues between a Japanese student and a Chinese student in New Crown (Morizumi, 1997), and dialogues between an Indonesian student and Japanese students in Everyday English (Ueda, 1997). However, the number of chapters that include this type of international use is considerably smaller than that of those representing international use between native and nonnative speakers. Most of the dialogues that are exclusively among nonnative speakers involve Japanese speakers and other nonnative speakers who are visiting or living in Japan, although one lesson in One World (Sasaki, 1997) includes a dialogue between a Japanese student and her Hong Kong friend that takes place in Hong Kong. International use between speakers from different inner circle countries is not represented in any chapters.

Although the international use of English exclusively among nonnative speakers is increasing (Smith, 1983), the textbooks that were investigated in this study do not reflect this trend. The predominant representation of the international use of English between native and nonnative speakers may give the impression that nonnative speakers learn English in order to communicate with those from the inner circle.

\section{Conclusion}

The current study explored the representation of uses and users of English in Japanese 7th-grade EFL textbooks. The findings suggested that these textbooks tended to emphasize the inner circle, both in intranational and international use. English users from the inner circle were presented as the primary users of English, and the majority of chapter dialogues that took place outside of Japan were situated in the inner circle. The predominant users of English for intranational communication were also those from the inner circle, and the majority of international use presented involved communication between native (i.e., the inner circle) and nonnative speakers. The representation of users and uses in other contexts, particularly those in the outer circle and expanding circle countries other than Japan, was much more limited; there were fewer main characters from those countries, and their roles in dialogues were much more limited than characters from Japan or the inner circle. The representation of English use in the outer and expanding circles 
(except Japan), both for international and intranational uses, was also only sporadic. International use exclusively among nonnative speakers, which is believed to be increasing as a result of the worldwide spread of English (Crystal, 1997; Graddol, 1997; Smith, 1983), was represented much less often than that involving native speakers.

This inner-circle orientation in the representation of English users and use in these textbooks resembles the view of the ownership of English held by Japanese secondary school students (Matsuda, forthcoming). While a causal relationship cannot be claimed without empirical verification, the similarity between students' perceptions of English users and use and the textbooks' representations, along with the significant role the textbooks tend to play in Japanese schools, suggests that the representation of English in EFL textbooks may be an important source of influence in the construction of students' attitudes and perceptions toward the target language. ${ }^{7}$

If we accept that textbook representation can influence students' perceptions of the English language and its users and uses, the representations found in these textbooks, which focus overwhelmingly on the users and uses of English in the inner circle and Japan and not on those in the outer circle and expanding circle countries other than Japan are problematic. Such a limited view of the language will not prepare students adequately to use English in the future with other nonnative speakers of English. In order to facilitate a better understanding of English users and uses, some changes in the textbooks are needed. For example, textbooks could include more main characters from the outer circle and the expanding circle and assign them bigger roles in chapter dialogues than the roles they currently have. Some dialogues that either represent or refer to the use of English as a lingua franca in multilingual outer circle countries could also be added to chapters. Also, the presence of characters from countries other than Japan and the inner circle would make the inclusion of cultural topics and pictures from those countries easy. Exposure to outer circle and expanding circle countries other than Japan through the representation of English use and users in those countries would help students understand that English use is not limited to the inner circle.

Of course, teaching materials other than textbooks, such as teacher's manuals and commercial supplementary materials, as well as other aspects of teaching, including classroom practices and students' and teachers' attitudes, can supplement the textbook representation of the users and uses of English. For instance, movies, videos, audio clips, or 
interaction with international visitors and residents in the community can be incorporated into the classroom activities in order to help students understand that there are many varieties of English. While the American variety, given its preferential status in the current international communication scene, may be a reasonable choice as a target model in Japanese EFL classrooms, students must understand that it is just one of many varieties of English that they may come in contact with in the future. In addition, classroom discussions can address explicit statements in textbooks about the forms and functions of English, such as "Pronunciation of English varies in different countries and regions" (Shimaoka et al., 1997, p. 40) and "English is a world common language. It is an important means of communication when speaking with people from other Asian countries, too." (Sasaki, 1997, p.95). Textbooks may touch upon those issues only briefly, but classroom teachers can provide opportunities to address them in more depth.

English classes provide opportunities for an intensive encounter with the target language for EFL students. Japanese learners of English would benefit greatly from the thorough representation of the sociolinguistic complexity of the English language, including the various uses and users of the language found in different places of the world, in their English textbooks as well as in other components of the EFL curriculum.

\section{Acknowledgements}

I would like to thank Paul Kei Matsuda, Tracey McHenry, Kate Tirabassi, and Kensaku Yoshida, as well as Nick Jungheim and the anonymous reviewers for their comments and suggestions. This project was partially funded by the Center for the Humanities at the University of New Hampshire.

Aya Matsuda teaches undergraduate and graduate courses in linguistics and TESL at the University of New Hampshire. Her research interests include World Englishes and TESL.

\section{Notes}

1. The notion of native speakers as providers of standard, normative language has been challenged, as variability exists in what they know about the language, what they can do with the language, and what they consider to be standard. The 
notion of nonnative speaker is similarly problematic, especially with regards to English, because it fails to acknowledge the differences in the ways English users from the outer and expanding circles use the language and the fact that there are people in the outer circle who grow up speaking English as one of their primary languages (Kachru, 1998; Yano, 2001). While I hesitate to use terms that may reinforce the uncritical and inadequate dichotomy criticized above, I decided to use the term native speakers for English users from the inner circle and nonnative speakers for those from the outer and expanding circles in order to avoid wordiness when variability within each group is not as crucial in the discussion as the boundary between two groups.

2. Monbusho (Ministry of Education, Sciance, Sports, and Culture) became Monbu-kagaku-sho (Ministry of Education, Culture, Sports, Science, and Technology) after the reorganization of the governmental ministries on January 6, 2001. In this article, I continue to refer to the ministry as Monbusho because that was the ministry that examined and approved these textbooks in 1996.

3. The analysis of contexts and types of English was also conducted by using a smaller unit of analysis: a monologue and a dialogue. Each unit boundary was identified by a change in chapter, its context, and/or participants, and was analyzed in the same ways as described in the methodology section. Because the length of units varied, I also counted the numbers of conversational turns and words in order to make comparison possible. The findings did not vary greatly between the two sets of analysis employing different units of analysis. Since the use of dialogue/monologue as the unit of analysis involves greater variability than the use of preexisting chapters (because the researcher must identify the unit boundaries), only the results from the analysis that used chapters as the unit of analysis are reported in this paper.

4. Although Hong Kong is not a country, the use of English in Hong Kong illustrates characteristics of the outer circle, which differ significantly from those of English in mainland China, an expanding-circle country (see Bolton, 2000 for further discussion of English in Hong Kong). Therefore, Hong Kong 
is classified in this study as "outer-circle" and separately from China.

5. Both quotes were originally in Japanese and have been translated by the author.

6. I do not intend to suggest that Japan is a monolingual country, although Japanese is the dominant language of the society. See Maher and Honna (1994), Matsuda (2000b), and Yamamoto (2000) for discussions of linguistic diversity in Japan.

7. In order to better understand the influence of textbook representations on students' perceptions and attitudes, an empirical study that compares the perceptions of English users and uses held by different groups of students who use different textbooks and that compares the perception and the textbook representation for each group is needed. Furthermore, follow-up studies using the subsequent sets of textbooks would allow a diachronic comparison of language perceptions and attitudes.

\section{References}

Asano, H., Makino, T., \& Shimomura, Y. (Eds.). (1997). New Horizon English Course 1. Tokyo: Tokyo Shoseki.

Bardovi-Harlig, K. (1996). Pragmatics and language learning: Bringing pragmatics and pedagogy together. Pragmatics and Language Learning, 7, 21-39.

Berns, M. (1990). Context of competence: Social and cultural considerations in communicative language teaching. New York: Plenum Press.

Bolton, K. (Ed.). (2000). Special issue on Hong Kong English: Autonomy and creativity. World Englishes, 19 (3).

Crystal, D. (1997). English as a global language. Cambridge, UK: Cambridge University Press.

Friedrich, P. (2000). English in Brazil: Functions and attitudes. World Englishes, 19, 215-223.

Graddol, D. (1997). The future of English? London: The British Council.

Halliday, M. (1978). Language as social semiotic: The social interpretation of language and meaning. Baltimore, MD: Edward Arnold.

Hino, N. (1988). Nationalism and English as an international language: The history of English textbooks in Japan. World Englishes, 7, 309-314.

Horiguchi, T., Goris, R.C., \& Yada, H. (1997). Total English 1. Tokyo: Shubun Shuppan. 
Kachru, B. B. (1985). Standards, codification and sociolinguistic realism: The English language in the outer circle. In R. Quirk \& H. G. Widdowson (Eds.), English in the world: Teaching and learning the language and literatures (pp. 11-30). Cambridge, MA: Cambridge University Press.

Kachru, B. B. (1992). Models for non-native Englishes. In B. B. Kachru (Ed.), The other tongue: English across cultures (2nd ed.) (pp. 48-74). Urbana, IL: University of Illinois.

Kachru, B. B. (1998). English as an Asian language. Links \& Letters, 5, 89-108.

Maher, J. C., \& Honna, N. (1994). Towards a new order: Language and cultural diversity in Japan. Tokyo: Kokusai Shoin.

Matsuda, A. (2000a). Japanese attitudes toward English: A case study of high school students. Unpublished Ph.D. dissertation, Department of English, Purdue University.

Matsuda, A. (2000b). The use of English among Japanese returnees: A communicative strategy. English Today, 16 (4), 49-55.

Matsuda, A. (forthcoming). The ownership of English: A perspective of Japanese high school students. World Englishes.

Morizumi, M. (Ed.). (1997). New Crown English Series 1. Tokyo: Sanseido.

Sasaki, T. (Ed.). (1997). One World English Course 1. Tokyo: Kyoiku Shuppan.

Shimaoka, T., Aoki, S., Matsuhata, K., \& Wada, M. (Eds.). (1997). Sunshine English Course 1. Tokyo: Kairyudo.

Smith, L. E. (1983). English as an international language: No room for linguistic chauvinism. In L.E. Smith (Ed.), Readings in English as an international language (pp. 7-11). New York: Pergamon.

Togo, K., \& Matsuno, K. (Eds.). (1997). Columbus English Course 1. Tokyo: Mitsumura Tosho Shuppan.

Ueda, A. (Ed.). (1997). Everyday English I. Tokyo: Chukyo Shuppan.

Widdowson, H. G. (1994). The ownership of English. TESOL Quarterly, 28, $377-$ 389.

Yamamoto, M. (Ed.). (2000). Nihon no bairingaru kyouiku [Bilingual education in Japan]. Tokyo: Akashi Shoten.

Yano, Y. (1992). Foreign language teaching in Japan in the 21st century. AILA Review, 9, 63-68.

Yano, Y. (2001). World Englishes in 2000 and beyond. World Englishes, 20, 19131.

(Received February 26, 2002; Revised June 11, 2002) 


\title{
Perspectives
}

\section{An Algorithmic Approach to Error Correction: Correcting Three Common Errors at Different Levels}

\author{
Alice Y.W. Chan \\ City University of Hong Kong \\ Becky S.C. Kwan \\ City University of Hong Kong \\ David C.S. Li \\ City University of Hong Kong
}

An algorithmic approach to error correction characterized by four main features: pedagogically sound input requiring minimal cognitive effort, proceduralized steps with instructive examples, explicit rules helping learners conceptualize the correction procedure, and reinforcement exercises, is introduced in this article using three well-defined structural anomalies for exemplification: dangling modifiers, missing relative pronouns and the erroneous there has structure. The remedial instruction materials have been tried out with students at different proficiency levels and feedback was collected through different channels. Comments from both teachers and students indicate that such an approach is effective, versatile and flexible in helping Hong Kong Chinese ESL learners overcome persistent learning errors.

演算式(algorithmic)の誤り訂正には以下の 4 つの型一認知的努力が最小で教育 的効果のあるインプット、わかりやすい例による手順を追ったステップ、学習 者に訂正の過程がわかるような規則の提示、そして練習の強化一があるが、本 稿では、上記の誤り訂正法を 3 つのよく知られた構造的変則例を引きながら説 明する。3つとはぶら下がり (懸垂) 修飾、関係代名詞の欠如、 there has の誤 構文である。異なった能力レベルの学生に対し補修指導材料を使用し、フィー ドバックを様々な方法で収集した。その結果、教師と学生双方から、このよう

JALT Journal, Vol. 24, No. 2, November, 2002 
な方法が、特に香港の中国系ESL学習者の克服しにくいエラー修正に対して効 果があり、多目的に、柔軟性を持って用いることができるとのコメントが寄せ られた。

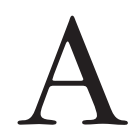

$s$ is well known, error correction is one of the most persistent problems confronted by second and foreign language teachers. Like many of our colleagues, we have frequently been disappointed by the fact that, despite various attempts to make our students aware of recurrent grammatical or structural problems, our students tended to make the same errors again in their language output shortly after corrective feedback was given, suggesting that students failed to internalize the correct model. A substantial body of research in Second Language Acquisition (SLA) has shown that learners may or may not notice the errors that they have made (cf. the noticing hypothesis, Schmidt, 1990, 1992), and even if a particular anomalous form has been noticed, the grammatical rule in question is often too abstract and complex to be mastered upon the teacher's corrective feedback. One possible reason is that the learner may have reached a plateau in the L2 learning process suggesting that fossilization has taken place. There may be other relevant factors, such as the degree of complexity of the grammatical phenomenon or phenomena in question, and whether the teacher is able to use relatively jargon-free metalanguage to make explicit fine structural nuances.

Advocates of the hard-core version of the communicative approach to language teaching tend to dismiss error correction for two main reasons: (a) the belief that all attempts to draw learners' attention to formal anomalies would discourage the learner from producing output in L2, which in turn would inhibit acquisition; and (b) the claim that there is no interface between learning (which takes place consciously with explicit instruction) and acquisition (which takes place subconsciously, typically through mere exposure to the target language in natural, meaning-oriented settings) (Krashen, 1981, 1982, 1985). However, a substantial body of recent research in SLA has shown that focus on form in context (Long, 1991; Long \& Robinson, 1998) or form-focused instruction in general (Spada, 1997) has great potential for enhancing the learners' language accuracy in their L2 output, thereby accelerating the rate of SLA.

In an attempt to improve the quality of our own remedial instruction, we experimented with an approach partly inspired by theoretical and 
empirical studies in consciousness-raising research (Sharwood Smith, 1981; Rutherford, 1987, 1988; Schmidt, 1990); and partly by more recent research on form-focused instruction and explicit corrective feedback (e.g. Doughty \& Williams, 1998; Granger \& Tribble, 1998), with an aim to explore the pedagogical potential of explicit, form-focused, corrective feedback in the Hong Kong ESL classroom. In our design of remedial instruction materials, we tried to analyze the learning task from the learner's perspective in order to make the remedial input cognitively accessible to even the weakest learners by minimizing the cognitive effort required to proceed from one proceduralized step to the next. We call such an approach an algorithmic approach to error correction (cf. Sharwood Smith, 1981), in the sense that there is a set of rules or procedures that students follow in order to overcome the lexico-grammatical problem in question. In more specific terms, the teaching approach that we have adopted in our materials is characterized by four main features (see Chan \& Li, 2002; Li \& Chan, 2000, 2001): (a) pedagogically sound input requiring minimal cognitive effort; (b) proceduralized steps supported by instructive examples; (c) explicit rules to help learners conceptualize the correction procedure; and (d) reinforcement exercises.

Such an algorithmic approach to error correction is versatile and flexible in that it can be used for error types of different complexity levels catering to learners at various proficiency levels. The remedial materials thus designed can be used either by teachers in the classroom with or without adaptation depending on the needs of their students, or for selflearning purposes by learners themselves. For this approach to work satisfactorily, however, one prerequisite is that the error type in question must lend itself to effective remedial instruction through a sequence of proceduralized steps. In this article, we will exemplify the algorithmic approach using the materials we designed for three error types at different complexity levels: dangling modifiers, missing relative pronouns, and erroneous there has structures. For ease of illustration, the correction procedure will be structured in different phases, with each phase focusing on one specific teaching goal and indicating what the teacher should or may do to help students overcome the error and progressively approximate the target structure.

Advanced Level: Dangling Modifiers 


\section{Nature and Causes of Problem}

Many advanced ESL learners have problems writing complex sentences involving a non-finite clause with no overt subject. The problem of dangling modifiers often results, as in the following two examples:

1.* $\quad$ Entering the stadium, the size of the crowd surprised John.

2.* Having eaten our lunch, the ship departed.

The core of the problem lies in the fact that the subject of the main clause cannot be interpreted as the subject of the subordinate clause/ non-finite clause. Inadequate knowledge of the correct usage of the target structure is probably the only cause of this problem. Students are unaware that the subject of the main clause (e.g., 'the size of the crowd' in sentence 1, or 'the ship' in sentence 2) has to be the same as the implicit subject of the subordinate clause/non-finite clause (e.g., "entering the stadium" in sentence 1, and "having eaten our lunch" in sentence 2).

\section{Correcting the Problem}

Phase One: Illustrate The Correct Use of the Structure with Correct Examples

1. Look at the following sentences:

(i) Entering the room, we turned on the light.

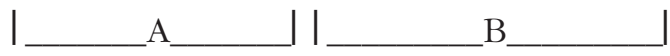

(ii) Walking along the streets, John met Mary.

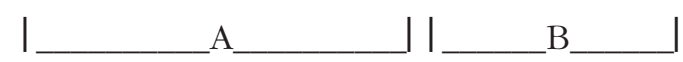

2. What is the subject of B in sentence (i)? Circle it.

3. Is there a subject in $\mathrm{A}$ ?

4 But do we know who entered the room? Who?

5. Compare the persons who entered the room and the subject of B. What do you notice? Are they the same persons or different persons?

6. Look at sentence (ii) now. What is the subject of B? Circle it. 
7. Who walked along the streets?

8. Again, compare the person who walked along the streets with the subject of B. Are they the same?

Phase Two: Introduce the Rule

9. In a complex sentence with two clauses, if the first clause (A) does not have a subject, the subject of the second clause (B) will be interpreted as its subject.

Missing Subject of A (subordinate clause) = Subject of B (main clause)

Phase Three: Help Students Notice the Core of the Error

10. Now let us look at sentence (iii) below. It has a similar structure to sentences (i) and (ii).

(iii) Entering the stadium, the size of the crowd surprised John.

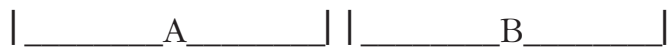

11. What is the subject of $\mathrm{B}$ ?

12. Can the size of the crowd be used as the subject of $\mathrm{A}$ ?

Phase Four: Highlight the Nature of the Problem

13. Sentence (iii) is wrong because the missing subject of A $\neq$ the subject of $\mathrm{B}$.

Phase Five: Help Students Correct The Sentence by Supplying the Appropriate Subject

14. So who entered the stadium?

15. Look at the rule in step 9 above.

What should be the subject of the second clause?

16. Rewrite B by changing the subject to John.

(iv) Entering the stadium, John

Phase Six: Reinforce the Correct Usage by Using Other Examples 
Phase Seven: Reinforcement Exercises

\section{Intermediate Level: Missing Relative Pronouns in Relative Clauses}

\section{Nature and Causes of Problem}

Another common error associated with the formation of complex sentences that ESL learners often make is the omission of a suitable relative pronoun in a relative clause as in the following two examples:

3.* I remembered the accident happened yesterday.

4.* There were altogether ten parents participated in the interview.

This error can be attributed to mother-tongue influence. In Chinese/ Cantonese, the mother tongue of most of the students in Hong Kong, there is no distinction between finite and non-finite verbs, and serial verb constructions with more than one verb/verb phrase juxtaposed in the same construction without having any markers to show the relationship between them are perfectly acceptable and very common. What complicates the situation is that the Chinese/Cantonese sentences corresponding to sentences 3 and 4 do not require a relative clause structure or a relative pronoun (see sentences 5 and 6 below). It is thus not surprising for Chinese ESL learners to write English sentences with a chain of finite verbs. Here are two examples:

5. ngo5 gei3 dak1 ji3 ngoi6 si6 zok3 tin1 faat3 sang1 dik $1^{1}$

I remember accident is yesterday happen PRT ${ }^{2}$

6. zung2 gung6 jau5 sap6 ming4 gaa1 zoeng2 zip3 sau6 fong2 man6

total has ten $\mathrm{CL}^{3}$ parents receive interview

Apart from L1-related factors, the allowance of a seemingly similar structure in English also contributes to L2 learners' misunderstanding of the correct usage. Sentences such as 7 and 8 below, containing a reduced relative clause with the relative pronoun and the finite verb omitted, may cause confusion. Learners who are unaware of the differences between the acceptable reduced relative structure and the erroneous sentences 
may incorrectly apply the rule of omission of relative pronouns. Here are two example sentences:

7. I like her book published last year.

8. I have seen some of the parents interviewed.

\section{Correcting the Problem}

Phase One: Help Students Notice the Error

1. Are the following sentences correct?

Make a "口"if you think so, and a "口" if you don't think so.

(i) Mary likes John's book published last year.

(ii) I met two parents attended the interview yesterday.

(iii) I remember the accident happened yesterday.

(iv) We note from the reports appeared at the front page of the SCMP.

(v) There were altogether twenty students took the test.

Phase Two: Explain the Acceptability of the Grammatical Sentences by Highlighting the Voice of the Verb Concerned (Whether it is in Active or Passive Voice)

2. Compare sentences (i) and (ii).

(i) 4 Mary likes John's book published last year.

(ii) I I met two parents attended the interview yesterday.

3. Look at sentence (i). What does Mary like?

4. What happened to John's book last year?

5. Note the correct pattern.

uJohn's book published last year.

uJohn's book was published last year.

6. Rewrite sentence (i) into two simple sentences, A and B. B 
7. Circle the noun phrase which is found in both A and B.

8. Since John's book is found in both A and B, we can turn $\mathrm{B}$ into a relative clause. Which relative pronoun (e.g., which, who, whom, whose, that) can we use?

9. Combine $\mathrm{A}$ and $\mathrm{B}$ using the relative pronoun suggested.

10. Observe: Is the verb published in the active or passive voice?

11. What is the form of the verb published? Is it a present tense verb, a past tense verb, a present participle, or a past participle?

Phase Three: Make Explicit the Context Where Relative Pronouns Can Be Omitted

12. Since published is a participle, the subject relative pronoun and the verb to be can be deleted. Here is an example:

(vi) [ [ I like her book ] [which was published last year.]

A

B

In a complex sentence $\quad[\ldots$ VERB $\ldots$ VERB ... $]$

A B

If $\quad \mathrm{B}$ is a relative clause and the VERB in $\mathrm{B}=$ PARTICIPLE

Then Subject relative pronoun and VERB TO BE can be deleted

Phase Four: Explain the Unacceptability of the Ungrammatical Sentences

13. Now, look again at sentence (ii). Who did I meet yesterday?

14. What did the two parents do?

15. Which is correct?

Two parents attended the interview; or

Two parents were attended the interview. 
16. Rewrite sentence (ii) to form two simple sentences, $\mathrm{A}$ and $\mathrm{B}$.

A

17. Circle the noun phrase that is found in both A and B.

18. Replace the noun phrase in B by a suitable relative pronoun. (e.g., who, which, etc.)

19. Combine A and B using the relative pronoun suggested.

20. Observe: Is the verb attended in the active or passive voice?

21. What is the form of the verb attended? Is it a present tense verb, a past tense verb, a present participle, or a past participle?

Phase Five: Spell Out the Context Where a Relative Pronoun Must Be Used

22. Since attended is not a participle, the subject relative pronoun cannot be deleted.

In a sentence $\quad[\ldots$ VERB ... VERB ...]

A B

If $\quad B$ is a relative clause and Verb in $\mathrm{B} \neq$ PARTICIPLE

Then a relative pronoun must be used

(vii) 0 [ I met two parents ] [ who attended the interview yesterday ].

(viii) 0 [ I met two parents ] [ attended the interview yesterday ].

Phase Six: Introduce Alternative Ways of Combining Clauses

23. Following the first rule in step 12, we can rewrite sentence (viii) by changing the verb in B to an -ing participle. The subject relative pronoun can be deleted.

Here is an example:

(ix) 0 [ I met two parents ] [ attending the interview yesterday ]. 
Phase Seven: Reinforcement Exercises

Elementary Level: the Erroneous 'There has' Structure

Nature and Causes of Problem

As far as elementary ESL students in Hong Kong are concerned, the mistaken construction of the 'there be' structure is one of the most common problems that occurs. The verb HAVE is often misused in place of the verb to $\mathrm{BE}$ to express the existential or presentative function, as in the following:

9.* There has a book on the table.

10.* There have many computers in the room.

The probable causes of this structural problem are both L1 and L2 related. First, the corresponding existential meaning in Chinese/Cantonese is expressed using jau 5 'have', rather than the verb to BE as used in English. Here is an example:

11. maa5 lou6 soeng6 jau5 han2 do1 ce1 road above has many cars

Second, the dummy subject 'there' in a 'there BE' sentence is often mistakenly regarded as syntactically and semantically equivalent to the Cantonese sentence-initial adverb go 2 dou 6 '(the demonstrative) there' (as in example 12). This, coupled with the misuse of 'have' to mean the existential yau 5 in Chinese, results in the erroneous 'there has/have' structure as in sentences 9 and 10 .

12. go2 dou6 jau5 hou 2 do1 jan 4

there has many people

Negative transfer from L1 is not necessarily the only reason that may account for students' problems with the structure. Students' inadequate mastery of the different forms of the verb to $\mathrm{BE}$ in the target language may also contribute to the error. As the perfect forms 'have been' and 'has been' of the verb to BE are morphologically similar to the verb HAVE, probable confusion due to such acceptable structures as sentences 13 and 14 may also lead to the anomaly.

13. There have been a lot of visitors in Hong Kong.

14. There has been a dog sleeping there. 
Correcting the Problem

Phase One: Alert Students to the Constituents of the Target Structure

1. (T shows a picture.) Look at the picture. What is on the tree?

(i) A bird is on the tree.

2. Sentence (i) tells us that [ something ] IS/ARE

[ somewhere]. But to say that [something] IS/ARE

[ somewhere ], you can also say There BE [ something ]

[ somewhere].

[ something ] IS/ARE [ somewhere ]

There BE [ something ] [somewhere ]

3. What is something in sentence (i)?

4. What is somewhere in sentence (i)?

5. Now, rewrite sentence (i) using the There BE structure shown above.

Phase Two: Consolidate Students' Understanding by Comparing the Target Structure with a Familiar Structure

6. Now compare sentence (i) with the rewritten sentence.

(ii) There BE

a bird

on the tree.

(i)

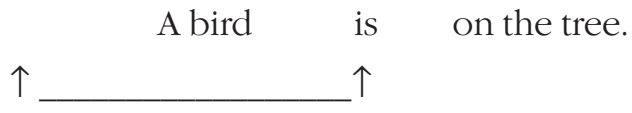

7. We can't use $B E$ as the verb of the sentence. Cross out $B E$ and move the verb is to the position after There.

8. Now, can you answer the question again: What is on the tree?

Phase Three: Reinforce Students' Understanding by Using Other Examples

9. Let us look at another picture (two pictures hanging on the wall): What are on the wall? 
(iii) are

$$
\text { something somewhere }
$$

10. What is something in sentence (iii)?

11. What is somewhere in sentence (iii)?

12. Following the rule in step 2 above, rewrite sentence (iii).

13. Again compare sentence (iii) with the rewritten sentence.

(iv) There BE two pictures on the wall.

Two pictures are on the wall.

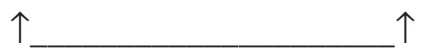

14. We can't use $B E$ as the verb of the sentence. Cross out $B E$ and move the verb are to the position after There.

15. Now can you answer the question again: What are on the wall?

Phase Four: Help Students Notice the Nature of the Erroneous Structure

16. Now look at the following sentence. What's wrong with it?

(v) $\times$ There has a book on the table.

17. What is something in sentence (v)?

18. What is somewhere in sentence (v)?

19. Can we say $A$ book has on the table?

Phase Five: Highlight the Nature of the Problem

20. Since we can't say A book has on the table, we can't say There has a book on the table.

[ [ something] has [ somewhere] $\mathrm{C}$

口 There HAS [ something ][somewhere ]

Phase Six: Reinforcement Exercises with and without Contrastive Examples 
Dangling modifiers, missing relative pronouns and erroneous therehas structures, are all morpho-syntactically well-defined error types, which lend themselves very well to error correction through the algorithmic approach. These three sets of materials, together with those designed for ten other error types such as resumptive pronouns and faulty parallelism, have been tried out in an ongoing research project, which involves six secondary and tertiary teachers who used the materials in class with their students (over 200 in total), as well as a number of tertiary students ( 21 in total), who used the materials in a self-learning mode. Feedback on the materials was collected through focus-group meetings with teachers, post-teaching protocols filled out by participating teachers, and self-access evaluation forms filled out by students. In this section, we will briefly examine their responses.

The participating teachers found the materials effective, in that their students became better aware of the problems in the erroneous structures and hence were able to correct them. They also reported that their use of the taught items improved, and the materials helped them gain concrete grammar knowledge. Comments given in the self-access evaluation forms filled out by the students who used the materials in a self-learning mode, also reflected that the materials helped them see the gist of the problems in the erroneous structures as they corrected the errors.

Responses to the user-friendliness features of the materials were on the whole positive. The teachers found the proceduralized correction steps and the rules provided in the materials straightforward and clear enough to help students see and rectify the erroneous structures. The students were also able to follow the materials with little difficulty.

Most of the students who used the materials in a self-learning mode commented on the self-evaluation forms that the materials were clearly written and easy to follow, with the majority of them being able to finish the steps within 30 minutes.

\section{Conclusion and Adaptation}

In this article, we have demonstrated how an algorithmic approach to error correction can help learners at different proficiency levels overcome persistent, common English errors. Our experience suggests that, by virtue of the design features of the materials, the more structured the individual steps, the more likely that the approach will work. For more complex errors such as the dangling modifier problem, some use of grammatical jargon (e.g., main clause, subordinate clause) is inevitable if students are to master the subtle differences between the normative 
structures and the anomalies; yet for less sophisticated problems, technical terms should better be avoided. The algorithmic approach to error correction suggested here has received some empirical support, showing that it is effective, versatile and flexible with Hong Kong Chinese learners (Chan \& Li, 2002; Li \& Chan, 2000, 2001). It is our belief that properly administered, this approach will also work well with learners from other L1 backgrounds.

As might have been observed, some of the steps in the materials exemplified may appear to be rather redundant and repetitive. However, we need to emphasize that the repetitiveness is intended as part of the consciousness-raising approach we adopted. Since the materials target relatively weak students, extra guidance realized in explicitness and repetition is necessary to help students with the (re-)discovery of the rules. It is through explicitness that we raise students' consciousness of the tacit rules and through repetitions that we reinforce this consciousness. Having said this, we do not mean that repetitions are necessary all the time, nor do we imply that teachers need to follow every single step before students can arrive at satisfactory learning of the items. Rather, teachers are encouraged to adjust the steps based on their own knowledge of their students' proficiency and ability. At junctions where students' responses deviate from the expected "answers" to the leading questions, adaptations such as reformulating and re-ordering of the questions/steps are particularly essential.

The techniques suggested in this article, though pedagogically sound, are not meant to be exhaustive. They may not be useful for all sentences related to the error type in question and may have some lexical, contextual or structural constraints. Take the missing relative pronoun problem as an example. The technique proposed may not work well with all types of nouns and all types of verbs. Sentences with inanimate nouns such as * I found two books fell on the floor may not be corrected as easily as sentences with animate nouns such as the ones used in the remedial instruction materials (e.g., "I met two parents attended the interview yesterday). Another constraint is that since the materials were designed primarily to help students notice the correct use of sentences which contain a noun phrase with a relative clause as its post-modifier (either finite with an overt relative pronoun, or non-finite with no relative pronoun) (e.g., I met two parents who attended the interview yesterday / I met two parents attending the interview yesterday). Sentences whose surface structures bear resemblance to the erroneous structure but which do not contain such post-modification (e.g., I remembered you beat 
me yesterday) do not fit the evaluation metric suggested and hence are not targeted here. The subtlety of the varying degree of acceptability of sentences with unattached clauses is also an issue not addressed in our materials. Though sentences with dangling modifiers such as 1 and 2 are regarded as anomalous, other similar ones like To apply for the post, an application form must be submitted are less objectionable and may be acceptable to many native speakers of English. As the principal aim of our remedial instruction materials is to help students identify the nature of the anomalies and formulate a rule which governs the proper use of the structures, whether and when these subtleties should be brought to discussion is left to the discretion of the teacher. It is suggested that teachers take any form of adaptation needed to prevent learners from drawing erroneous conclusions.

\section{Acknowledgments}

The remedial instruction material described in this article was designed for a CityU strategic research project (grant no: 7000998). The support of the City University of Hong Kong Research Committee is acknowledged. We would also like to thank Ms. Emily Law for her administrative support, and the six participating teachers of the project for their cooperation and feedback.

Alice Y.W. Chan, Becky S. C. Kwan and David C.S. Li teach at the Department of English and Communication, City University of Hong Kong. Alice Chan's research interests include phonetics and phonology, contrastive analysis, syntax, lexicography and error correction. Becky Kwan's research interests include genre analysis, English for academic purposes and English for specific purposes. David C. S. Li's research interests include cross-linguistic influence, code-switching, World Englishes and intercultural communication.

\section{Notes}

1. Numbers represent tones (phonemic in Cantonese).

2. PRT is the abbreviation for Chinese sentence particles.

3. $\mathrm{CL}$ is the abbreviation for Chinese Classifiers such as ming 4, go3.

\section{References}

Chan, A.Y.W., \& Li, D.C.S. (2002). Form-focused remedial instruction: An empirical study. International Journal of Applied Linguistics, 12(1), 24-53.

Doughty, C., \& Williams, J. (Eds.). (1998). Focus on form in classroom second 
language acquisition. Cambridge: Cambridge University Press.

Granger, S., \& Tribble, C. (1998). Learner corpus data in the foreign language classroom: Form-focused instruction and data-driven learning. In S. Granger (Ed.), Learner English on computer (pp. 199-209). London: Longman.

Krashen, S. (1981). Second language acquisition and second language learning. Oxford: Pergamon Press.

Krashen, S. (1982). Principles and practice in second language acquisition. Oxford: Pergamon Press.

Krashen, S. (1985). The input hypothesis: Issues and implications. London: Longman.

Li, D.C.S., \& Chan, A.Y.W. (2000). Form-focused negative feedback: Toward a pedagogically sound model of remedial instruction. In D. C.S. Li, A. Lin \& W.K. Tsang (Eds.), Language and education in postcolonial Hong Kong (pp. 333-351). Hong Kong: Linguistic Society of Hong Kong.

Li, D.C.S., \& Chan, A.Y.W. (2001). Form-focused negative feedback: Correcting three common errors. TESL Reporter, 34(1), 22-34.

Long, M. (1991). Focus on form: A design feature in language teaching methodology. In K. de Bot, R. Ginsberg \& C. Kramsch (Eds.), Foreign language research in cross-cultural perspective (pp. 39-52). Amsterdam: John Benjamins.

Long, M. \& Robinson, P. (1998). Focus on form: theory, research, and practice. In C. Doughty \& J. Williams (Eds.), Focus on form in classroom second language acquisition (pp.15-41). Cambridge: Cambridge University Press.

Rutherford, W. (1987). Second language grammar: Learning and teaching. New York: Longman.

Rutherford, W. (1988). Consciousness raising and universal grammar. In W. Rutherford \& M. Sharwood Smith (Eds.), Grammar and second language teaching: A book of readings (pp.107-116). New York: Newbury House.

Schmidt, R. (1990). The role of consciousness in second language learning. Applied Linguistics, 11, 129-158.

Schmidt, R. (1992). Psychological mechanisms underlying second language fluency. Studies in Second Language Acquisition, 14, 357-385.

Sharwood Smith, M. (1981). Consciousness-raising and the second language learner. Applied Linguistics, 2, 159-169.

Spada, N. (1997). Form-focused instruction and second language acquisition: A review of classroom and laboratory research. Language Teaching, 30, 7387.

(Received January 13, 2002; Revised April 18, 2002) 